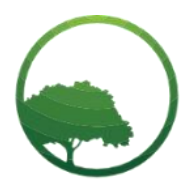

Research in Business \& Social Science

IJRBS VOL 10 NO 7 ISSN: 2147-4478

\title{
Farm-n-Pedia: Expert mobile agricultural knowledge-based system for Indian Farmers
}

\author{
(D) Ashmean Kaur Sran ${ }^{(a)}$ (D) Sherrie Y. X. Komiak ${ }^{(b) *}$ (D) Sabir Manzoor ${ }^{(c)}$ \\ ${ }^{(a, b)}$ Faculty of Business Administration, Memorial University of Newfoundland, St. John 's NL A1C5S7, Canada.

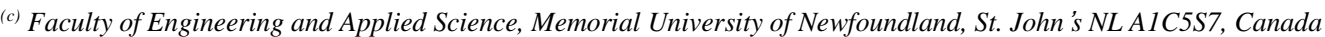

\begin{tabular}{l} 
A R T I C L E I N F O \\
\hline Article history: \\
Received 04 October 2021 \\
Received in rev. form 25 Oct. 2021 \\
Accepted 29 October 2021 \\
Keywords: \\
Agriculture app, Knowledge-based \\
system, social media, crowdsourcing, \\
farming, crop productivity \\
JEL Classification: \\
L15
\end{tabular}

\begin{abstract}
A B S T R A C T
Efficiency in farming productivity and optimum utilization of resources in the agriculture sector in developing countries is a challenge that can be addressed with technological advancement. There is also a strong need to work on the farming community's engagement to make better farming decisions. This study aims to create an expert knowledge-based system (KBS) in a mobile application to help Indian farmers improve their agricultural practices and increase crop productivity. A prototype mobile application, 'Farm-n-Pedia, 'is designed and used to fulfill the farmers' informational and engagement needs. It provides a tool for agriculture management using a single platform. The expert KBS incorporates a crowdsourcing system as part of the knowledge base and interface design. The mobile application enables the users to access the worldwide information they want, get personalized expert guidance, interact with the local agrarian community, know about the latest farming techniques and technology, crowdsource data collection and increase agricultural productivity.
\end{abstract}

(C) 2021 by the authors. Licensee SSBFNET, Istanbul, Turkey. This article is an open access article distributed under the terms and conditions of the Creative Commons Attribution (CC BY) license (http://creativecommons.org/licenses/by/4.0/).

\section{Introduction}

India enjoys a unique combination of climate and geography, making it the $10^{\text {th }}$ largest arable land in the world (Singh et al., 2020). It comes as no surprise that India has 20 agri-climatic regions, and all of the world's 15 significant climates exist in India (Singh et al., 2017). Agriculture is a primary source of income generation for 58\% of the Indian population (India Brand Equity Foundation, 2020), but it only contributes $14 \%$ to the national GDP (Singh et al., 2020) as compared to the service sector, which contributes a substantial $59 \%$ to GDP with only $23 \%$ of the workforce (Lakshmanan, 2019). Furthermore, as India is the second-most populous country globally with 1.371 billion (2019) people (United Nations, 2019), providing food security is an ever-growing concern. The Indian government is trying its best to adapt farming according to the growing population by increasing food grain production with agricultural scientists' help (Veeranjaneyulu, 2014a). Thus, the agricultural sector's output has become a crucial part of India's national development plan for global competition. It poses a unique challenge for Indian agriculture in terms of future growth, and it requires urgent attention and out of the box solutions to properly channel the workforce in utilizing the potential of the Indian agricultural sector.

There is no surprise that India is thriving as one of the top food-producing countries in the world, but it is also very clear that the agricultural techniques need upgradation by integrating with disruptive technologies. The agriculture sector is undergoing a technological transformation to combat with the future challenges like food security and climate change. With the huge manpower employed in agriculture, India has the capacity to increase the agrarian production with the use of advanced technology. Technologies and innovative methods like Internet of Things (IoT), automation, crowdsourcing and geospatial technologies can bring a whole different era for the agrarian sector.

\footnotetext{
* Corresponding author. ORCID ID: 0000-0001-8649-9866

(C) 2021 by the authors. Hosting by SSBFNET. Peer review under responsibility of Center for Strategic Studies in Business and Finance. https://doi.org/10.20525/ijrbs.v10i7.1437
} 
The role of information technology is changing in our everyday lives, and our dependence on it increases. Technology has made it possible for the farmers to accumulate their production records and share them with agricultural experts whenever the need arises. The question is: How easy and how accessible is the technological upgradations for the farmers? People often misjudge agriculture as an easy practice, but it requires high precision and knowledge (Sran et al., 2020). However, the agricultural sector employs many people with low literacy levels and often have little knowledge about farming practices. The farmers end up investing in expensive agricultural machinery that might be unfit according to their agricultural land, overuse of fertilizers that badly affect soil fertility, and other exploitation and wastage of resources, which all occurs because of lack of proper information (Murria, 2018). Information and Communication Technology (ICT) can act as a source to provide support to the farmers by disseminating useful information related to agricultural improvements, variable prices of inputs, market updates, agricultural know-how, among others. Fulfilling the farmers' informational needs can help them in optimum utilization of the agricultural resources and generate maximum profits with increased crop productivity (Armstrong et al., 2012). The farmers need appropriate training according to their individual needs, and we aim to design a mobile application that can provide personalized assistance to them and many other smart farming features. ICT can also help bridge the gap between agricultural extension scientists and farmers, leading to improved agricultural research, education and expansion (Singh et al., 2015).

Smart farming uses various technologies and devices like the internet, cloud-based data, and IoT devices, aiming to reduce manual work and automate agricultural activities. It has been adopted in some developed countries, but developing and under-developed economies struggle to practice smart farming. Tech farming, which includes a wide range of new tools like robotics, ICT, earth observations, and big data, is still in India's experimental phase. The first hurdle to use ICT technologies in Indian farming activities comes from the farmers themselves. Farmers are deeply dependent on traditional agricultural practices and have little or less awareness of technological advancements. The main reasons are lack of literacy, fear of technology, the narrow spread of technology in rural areas, and resistance to shifting from traditional to tech-savvy methods (Marimuthu et al., 2017).

There is a need to bridge the gap between information technology and the agriculture sector, and through this paper, we propose a unique prototype knowledge-based system enabled with crowdsourcing and social media features to make it interactive, attractive and one-stop for all farming solutions for the farmers. It aims to bring a close-knit community of farmers, make them knowledgeable about the agricultural sector's technological advancements, provide expert guidance from the agricultural scientists, and increase crop productivity.

Introducing technology in the agricultural sector can empower the farmers, build a strong community, increase their efficiency, and improve competitive dynamics. It has been observed that farmers fail to put their true potential towards farming activities due to a lack of resources and less knowledge. ICT tools can improve crop monitoring, track employee working hours, weather forecasting, crop management, information access, and other activities with the vision to increase popularity among the farmers and help them perform day-to-day activities. A mobile knowledge-based system (KBS) can serve as a platform to disseminate agricultural information gathered by experts in their research laboratories globally to the ultimate user, i.e., farmers and field workers. Farmers perceive "fellow farmers" as the preferred source of information over the government and private companies because of less biasness (Marimuthu et al., 2017). Having this point in mind, we collaborated expert guidance with fellow-farmers' trust through a social media-enabled knowledge-based system for the farmers. It fulfils the farmers' problem-solving and informational needs and helps them in farm management practices. It also aims to build farmers' trust in the agricultural researchers and government and empower them to make the right farming decisions, raising farming standards. It explains the motive behind the notion of a mobile application prototype 'Farm-n-Pedia.'

The idea is to incorporate a social media platform as part of the knowledge-based system for the farmers. It will increase its popularity among the farmers and provide them with expert guidance for their farming activities. The prototype framework is designed to accommodate thriving technological advancements, a broad application spectrum, and flexibility for usage and adoption with the changing needs. With the social media aspect's involvement, we aim to take this platform to every agricultural household and make it part of their lives, even in remote rural areas. It can bring agricultural awareness among the farmers and has the potential to bridge the digital divide in rural and urban areas. We hope that our proposed mobile app can provide accessibility to localized, personalized, and dynamic knowledge for the farmers in performing day-to-day farming activities.

The rest of the paper is organized as follows: Section 2 summarizes a literature review based on usage of knowledge-based system, social media and crowdsourcing in agriculture. Section 3 explains the research motive, scope and features of the mobile app prototype that we developed for Indian farmers along with detailed description of the knowledge-based system architecture. The technical framework and development of the mobile application is discussed in Section 4. It also includes use case and model representation of the app structure. Furthermore, discussions and explain the contributions made by this study are highlighted in Section 5 of the paper. Finally, Section 6 draws conclusions and future study directions.

\section{Literature Review}

\section{Agricultural knowledge-based system}

In this section, we have gathered research on the usage of Information Communication Technologies (ICTs) to increase productivity in the agricultural sector and rural development. A study was conducted by Allahyari \& Chizari (2010) to identify the possibilities 
of new technological advances in the agricultural and rural sectors. It revealed that most of the countryside's technology applications were used to provide training activities for rural inhabitants and transfer knowledge between urban and rural areas. The research emphasized using e-trade for farm-related input-output, Geographic Information System (GIS) for natural resources management, and official procedures for improving agricultural productivity, reducing rural poverty, and developing the people's livelihood. Megan suggests that the agricultural community can be empowered by introducing ICT to it (Megan \& Donnell, 2013). ICTs can help in increasing efficiency and improved competitive dynamics. She focused on developing a list of guiding questions that developers can ask from the target audience to make ICTs more popular. Behaviour changes among farmers have been listed as an essential parameter under her research. Jain \& Kumar (2017) developed an ICT model intending to strengthen agricultural standards. They measured the farmer's attitude and knowledge level towards technology-based agrarian services and found that many farmers were unaware of the technological use in farming practices.

Some analysts worked on providing hands-on information to the farmers for agricultural efficiency improvement. Mittal concluded that quality information could improve agricultural productivity and efficiency. He highlighted that IT could bring qualitative improvement in farmers' lives by providing well-timed and quality information for better decision-making (Mittal, 2016). Most of the field workers and farmers find it hard to access the latest news related to farming, making it hard for them to make effective decisions. Mittal focused on the techniques that can be used for the welfare of the rural population and to provide them with information about technological advancements. According to a research by Mwakaje (2010), in Tanzania, farmers and traders dominate the market information sources using ICTs. Accessing market information, weather forecasting, the latest farm technology information was made possible with ICTs. $23 \%$ of the total farmers used ICTs for tracking market prices and gained higher rates for their produce in the market than the farmers who used traditional methods of seeking information. The use of ICTs is not widespread due to the cost involved, lack of accessibility and perception of low reliability among the farmers.

Public, private, and cooperative sectors also play an essential role in the development of the agricultural sector. According to Saravanan et al. (2015), many private and public mobile advisory services in India are initiated by the state and central government. However, most of them have regional restrictions due to language barriers and state-specific information. Meera, Jhamtani, \& Rao did a comparative analysis for performance assessment of three projects working on agricultural development in India (Meera et al., 2004). All three projects had distinct purposes run by public, private and cooperative sectors but a common ground to improve information delivery for farmers and rural populations. The projects provided advisory services to the farmers, information about rural development programs, and other useful information from private sources. Farm management information and frequently asked questions were provided under the cooperative sector project, whereas the public sector provided access to land records, market information and government development policies. The private company started rural development programs and provided information for crop infection management to the farmers.

We also came across researchers that focused on studying the impact of expert systems on agriculture. Singh \& Hussain (2018) did a critical review of expert systems that address the Indian farmers' on-site problems by integrating the expertise of various disciplines such as soil management and horticulture. Narechania (2015) developed a mobile application to provide farmers with government helplines, news, market prices, and weather forecasts. It also controls water pumps to irrigate small fields using mobile and Bluetooth networks. Singhal, Verma, and Shukla (2011) have developed an android based mobile application to provide information about crop prices, farmer loans and weather to the farmers (Singhal et al., 2011). These studies' main idea was to highlight expert systems' use so that ordinary farmers upgrade to the expert level. Furthermore, various applications like Kisan Suvidha, mKrishi, and KrishiKosh (Veeranjaneyulu, 2014b) focus on providing aids to farmers, but they cover only a specific set of objectives.

Numerous agricultural universities and research centers have provided detailed knowledge to the farmers, but it is inaccessible in remote areas. Besides, scalability of the expert information becomes difficult as there are a large number of farmers globally who aspire to seek expert information for their farm practices but only a few research centers. Agricultural Management is very crucial for efficiency in farming practices. Globally, 6 million dollars (approx.) are spent by the public and private sector in improving farming, but their main focus is towards the needs of large farmers (Dwivedi et al., 2013).

\section{Social Media and Crowdsourcing in the Agricultural Sector}

Social media enables people to create, share, collaborate, discuss, and network through a wide range of new digital platforms (Balkrishna \& Deshmukh, 2017). It is a revolution that has been wholeheartedly accepted by people, but there is evidence that social media has not yet fully reached the agricultural sector. Pechrová, Lohr \& Havlíček found out that integrating social media into the farmers' lives is not an easy road and might face difficulties due to their lack of familiarity with social media (Pechrová et al., 2015). Since this form of communication is not part of their daily routine, it might be challenging to create social media awareness and make it the new normal. Knowledge transfer from researchers to farmers is vital to increase agricultural resilience and overcome challenges like food security and climate change sustainable intensification. The use of ICTs in agriculture has increased in the past few decades in India to improve production efficiency and increase profitability but using social media in agriculture is quite a new concept. We have gathered a few studies based on the potential to adopt social media in the agricultural sector in developed economies. Morris \& James (2017) identified barriers and objections in adopting social media by agriculture-based enterprises. They adopted a case study approach to understand current agricultural Facebook pages and Twitter accounts and came across a conceptual model to improve farming practices and entrepreneurial activities. According to Klerkx, Hall \& Leeuwis, agricultural researchers, advisors, and 
policymakers follow a collaborative social network approach to include farmers in creation, diffusion, adaptation, and use of knowledge and in providing other resources for innovation (Klerkx et al., 2009).

The researchers have looked at the agricultural marketing aspect of social media and have highlighted the current scenario and outlook of people towards the adoption of social media in agriculture-related service industries. Simmons, Durkin and others analyzed small and medium agri-food companies claim that the adoption of online business resources has been hampered by a lack of marketing capability and a negative attitude towards internet adoption (Simmons et al., 2007). The business sector has deeply integrated social media in its practices to communicate with the customers, and farming cannot be left alone in this dynamic process (Rapp et al., 2013). Academic literature published for understanding social media trends in agriculture is limited (Rhoades \& Aue, 2010). Social media websites are identified as a critical source of information gathering, and these platforms can also be used as a key data source for providing a decent global market exposure to the small farmers or markets and help them engage with more customers (Pechrová et al., 2015).

Crowdsourcing is a new approach in the agricultural sector, so it also has limited literature. It can greatly benefit the farmers and agrarian researchers in increasing crop production and improving agricultural practices. Crowdsourcing is a technique of engaging a large number of people from a broader reach to obtain the needed services, ideas, or useful information. According to research conducted in the Democratic Republic of Congo, mobile crowdsourcing pulls favourable results in agricultural development in terms of data accessibility and providing support in the decision-making process. They used the Short Message Service (SMS) of an agricultural profiling and messaging service named Esoko for information sharing among the farmers (Kahasha \& Zuva, 2020). Another crowdsourcing based study was conducted in two Indian states to investigate crowdsourced data's ability to increase or substitute extensive scale land surveys for land use mapping (Wang et al., 2020). It can be observed that due to limited research in the use of crowdsourcing concerning agriculture, there are still a lot of untapped avenues that can be explored and might result in deriving disruptive dimensions to the agriculture sector.

\section{Proposed Design}

Based on the literature review, it is evident that different studies have been done on the ICTs and mobile applications that have helped the farmers in seeking agrarian information. Various sources of informative material like forecast systems, informative videos, decision-support systems, and text services are available to link farmers and advisors. However, the scope of social media and crowdsourcing in agriculture is still untouched and need exploration. Therefore, we have created a prototype model (Farm-n-Pedia) of an agricultural knowledge-based system (KBS) (Joan, 2015) for Indian farmers, using crowdsourcing social media to provide realtime decision support to the farmers. Not only this, but the crowdsourced data also gets accumulated in the knowledge-based system for future referencing and to assist other farmers. We propose integrating the agricultural KBS system model (Sran et al., 2020) with social media features to make the mobile application more interactive for the farmers and add the much needed real-time approach. It aims to have databases from inline advisory systems of the Indian government and certified websites to provide personalized solutions to the farmers' concerns. We intend to deliver the latest, real-time, and locally personalized information related to the agricultural management system to the farmers all in one place.

Expert systems are designed to address the problem of knowledge transfer from highly qualified specialist to the people who have less knowledge (Rafea \& Shaalan, 1996). The knowledge-based system (KBS) has been developed for Indian farmers to meet their informational needs and improve crop productivity through a single platform. It operates on a global positioning system (GPS), geographical information system (GIS), and mobile user interface to create a farm simulation for a tailored agriculture management system. Farmers will access the mobile app's database for general information related to the latest news and weather forecasts, a community portal for real-time interaction with researchers and farmers with similar specialization and receive the best possible solutions for their everyday problems. The software works on a self-learning framework to save all personalized solutions provided to the farmers for future reference. It will also help researchers understand the farmers' information-seeking patterns, crowdsource data for their research, and create trust bonds with the farming community.The production and application of site-specific farming can be made possible by integrating modern technologies with agriculture. Geographic Information Systems (GIS) and the Global Positioning System (GPS) are some of the tools used in western countries to increase their agricultural productivity and to provide farmers with ease of use (NOAA, 2014). It allows the pairing of real-time location information with precise data processing, leading to the study and effective handling of large quantities of geospatial data. This technology can be used in precision farming for farm preparation, field analysis, soil sampling, farm process guidance, different types of machinery such as tractors, harvesters, crop inspection for pest and insect diseases, variable rate applications, etc. The GPS can enable farmers to operate even under low-visibility field conditions such as mud, dust, fog, and darkness (Van Etten et al., 2019).

Additionally, the mobile application can be used by the farmers to interact with the local farming community in real-time and discuss the latest agrarian policies, market prices, latest machinery, labour, and other farm-related information. Social media's mass influence can benefit the agriculture sector on a large scale by engaging farmers, researchers, consumers, and market giants. The farmers can also harness the mobile app platform to discover entrepreneurial opportunities through micro branding and direct sales to consumers. There is a vast potential in using social media in the agriculture sector and can benefit many farmers worldwide. 


\section{Aim of Research}

This technology is very much needed because many Indian farmers are having less yield per hectare due to unfavourable weather conditions caused by climate change (Sran et al., 2020). This application enables farmers to keep track of crop production and make informed decisions for timely crop harvesting. Weather forecasts also play an instrumental role in precision farming, as it allows farmers to make cost-saving choices about when and how much to irrigate the fields. Weather predictions by Farm-n-Pedia enable growers to determine the right time to use fertilizers in their fields. The farmer can also use a portable tensiometer (Topp et al., 1984) provided by the app to analyze the farmland's current condition and assess if the field is moist enough for fertilizers to be worked in the soil. We aim to use the mobile application for providing various kinds of public information accessed through researchers and the government to support the decision-making of small and big farmers, local and centralized markets, public and private agencies, researchers, consumers and so on who is interested in the agriculture sector. People have different levels of knowledge and expertise in the agrarian sector, so we have made the mobile application so that anyone can seek its benefits according to one's informational pursuit or needs. Our main goal is to identify the personalized, real-time and localized informational needs of the users and address them efficiently using a one-stop solution to derive maximum satisfaction.

To spread social media among the farmers and promote the use of technology in agricultural industry, values like trust, engagement, transparency, and authenticity need to be present. Networking between farmers can develop a sense of belongingness and build more trust in the whole process. This platform can serve as a direct link between farmers and consumers, which will allow increased understanding of farming practices and increased consumer engagement in agriculture. Increased communication among farmers, market and consumers will bring much-needed transparency to the picture as well. The crowdsourcing approach can be combined with social media to add real-time factors and provide a more enriching experience to the farming community.

There is a long tradition of establishing participatory approaches in agricultural research projects to facilitate farmer-researcher interactions or agricultural data collection (Van Etten et al., 2019), but crowdsourcing through social media is a relatively new approach. Transmission of research and development expertise in agriculture is mostly coordinated by national or state agricultural departments or structures, known as extension programs, or by farm consultants from private firms to transmit technical knowledge and new technology to farmers. However, there is still a void between scientists and growers. Scientists may not recognize or even realize the desires of the farmer. Besides, often project outcomes do not reach farmers' fields or requirements, even though study outputs are significant. Recently, Beza, Silva, Kooistra \& Reidsma (Beza et al., 2017) introduced crowdsourcing of farm-related data as an innovative means to get field studies to perform yield gap analysis alongside sensor networks and remote sensing. Agriculturebased crowdsourcing applications include inputs that fulfill the agricultural researchers' needs and help close the knowledge transmission loop between researchers and practitioners and promote farmer-to-farmer interactions. Thus, we have incorporated a social media-based crowdsourcing system with the traditional knowledge-based system to make it more useful for the farmers and provide support to the agricultural scientists by giving hands-on data for enhanced agricultural research.

\section{Features}

The mobile app focuses on the problems faced by the farmers in their routine farming activities, their informational needs to keep them updated with technological advances and policy updates by the government, a crowdsourcing platform for data collection and the creation of an online agrarian community for the farmers, researchers, consumers, and others who are interested in supporting farmers. The Farm-n-Pedia knowledge-based system allows the user to input their issue or useful information in textual, pictorial or both formats. For example, it will enable the farmers to share a crop infection related information or image to get expert advice from the KBS and researchers for overcoming the problem. It will also allow the farmer to share the crop infection information with local farmers to be made aware of a possible infection outbreak. The farmers can suggest solutions according to their knowledge and experience; the expert system can verify if the solution is appropriate to deal with the problem and provide a solution by referring to the knowledge base. Other than that, agricultural experts will also be able to access the platform for replying to the farmers' concerns and provide solutions. KBS can also suggest nearby stores where the farmer can get an insecticide by accessing their location. The data generated in the problem-solving procedure gets saved in the database, and a notification is generated for the farmers in the neighbouring areas to be aware of a potential crop threat and protect their crops. Farm-n-Pedia will thus promote a well-knitted farming support system and a reliable community for the farmers, which will help in flourishing the agricultural sector.

The features of Farm-n-Pedia include:

i. Personalized farm management system

ii. Real-time community interaction through social media

iii. Crowdsourcing enabled land use mapping and better identification of fields

iv. Farm planning and resource maintenance like records of fields, workers and machinery

v. Farm monitoring and task assignment features for work-breakdown with reminder add-ons

vi. Compare crop production on a seasonal or yearly basis

vii. Monthly progress reports and data storage for future reference

viii. Online and offline decision support system with expert guidance

ix. Crop inspection for insect and pest management

x. Data collection for research projects 
xi. Information and agriculture news updates in regional languages

xii. Weather forecasts

xiii. Historical farm data tracking

xiv. Learning about the latest farm techniques and advanced machinery

xv. Self-learning system based on user interaction

xvi. Direct interaction with the market and consumers to understand market demands

xvii. Suggestions for resource management techniques

xviii. Tutorials to use agricultural machinery for novice farmers

xix. Determine soil fertility and crop recommendation based on soil type

Our knowledge-based system's portable application aims to provide farmers with a highly interactive agrarian community focused on moving towards the betterment of the agriculture sector. It is a modern social media approach combined with the benefits of an agricultural management system that provides localized and dynamic information according to the users' needs and desires. The tailored experience makes it a unique approach to address farmers' routine concerns and offer the best possible solution. Not only this, but the farmers will also get an opportunity to interact with the researchers and be part of agricultural innovation projects for a more significant impact. The farmers can act as citizen scientists and help the researchers generate data for coming up with solutions to overcome the climate change-related issues, develop new crop seeds for increasing crop production, and other small and big projects. With regards to the agricultural management system, farmers can also keep track of crop production done annually and their profitability reports. With the application, the farmers can record land profits and keep notes on the app's virtual farm simulation as they move around the fields. The data will be saved in the app cloud and linked with the farm coordinates using the geolocation algorithm (Sran et al., 2020). Cloud data can ultimately be converted into graphical representation to better understand agricultural productivity (Information Solutions, 2015). Thus, the government can use the database to track agricultural production, scientists can use it for their research projects, and market buyers can use it for production estimates and initiating purchases from the farmers.

\section{Methodology}

Figure 1 shows the overall structure design of the improved expert knowledge-based system.

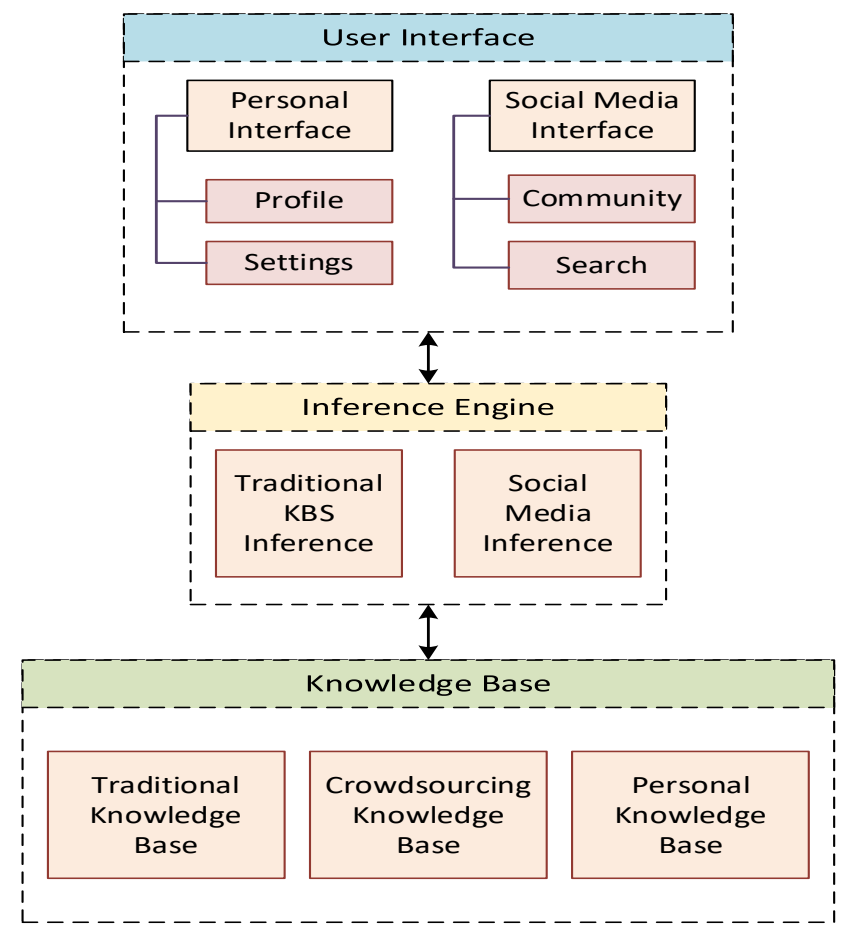

Figure 1: Conceptual Model for the Expert Agricultural Management System

Unlike the traditional expert knowledge-based system, our mobile app has extended the main modules of the user interface, inference engine, and knowledge base into submodules. The user interface got an additional social media interface and the standard personal user interface, which gives the user an advantage to interact with the world in real-time. The user can utilize the personal interface at the same time for farm management, updating land information, managing personal information stored on the app, among others. When users open the mobile app and go to the social media interface, they interact with the expert system and other users, which helps them decide upon a feature of interest to seek information or find a solution. The social media interface provides an unmatched opportunity to the user to create direct links with the local farming community, researchers and market experts for support. The 
inference engine gathers the data received through the social media interface as input for storage in the knowledge base after validating it using expert knowledge. The inference engine is further divided into traditional KBS and social media inference. Here, the traditional KBS has pre-defined algorithms as part of the decision-making process for providing the best solutions to the user. The social media inference adds a layer of decision-making based on the real-time solutions provided by different users, including farmers and researchers. Our expert knowledge-based system allows the user to add personalized data/knowledge to the knowledge base for future referencing and for helping others. The knowledge base consists of a traditional knowledge base with textual and pictorial information collected from government sources, local experts, journals, and databases. The knowledge base also has a crowdsourcing knowledge base that stores system verified queries of the users with the best answers and general information shared by the users, which can be used by the scientists for research purposes. The inference engine consults the domain experts and farmers to understand the goals and attributes of information seeking to provide more tailored solutions. The structure of the diagnostic rules and constraints was discussed with agricultural experts before developing the expert knowledge-based system. The system stores the user's farm-related information in a personal knowledge base and their social media history as a backup for easy referencing. It also fulfils the researchers' crowdsourcing needs by acting as a source to collect hands-on information from the farmers.

\section{Knowledge Base}

A knowledge base is a storage place where the app stores all databases used to access, manage, and share important information with the users. It contains information related to all potential queries from a user and acts as a one-stop solution for users' everyday concerns. The knowledge base has been divided into a traditional knowledge base, crowdsourcing knowledge base and personal knowledge base.

\section{Crowdsourcing Knowledge Base}

With the main objective of user-friendliness and result oriented Farm-n-Pedia mobile application, in-depth analysis of the information-seeking goals and parameters was conducted to develop the interactive facilities adding, viewing, modifying, deleting of information searched provided by the user. Experts feed the accumulated knowledge to the knowledge base and reserve it in a structured form to maintain database consistency through the system. The researchers' real-time updated data derived through the social media interface can be used for data crowdsourcing to support their scientific studies. The system combines information generated through real-time suggestions and feedbacks in the social media discussion forum with the crowdsourcing knowledge base for storing updated and technical information about a particular issue. The experts confirmed the reliability of the information, and the farmers provide its actual feasibility ratings after testing, so the system self-learns with each input made by a user. It removes duplicate issues and combines them to calculate better reliability and feasibility estimates for each issue. The information results provided are prioritized based on the feasibility and reliability estimates to build a wide-ranging knowledge base for the users.

\section{Traditional Knowledge Base}

The traditional knowledge base contains up-to-date databases about the present and historical weather and climatic changes information; soil maps and database to ascertain soil fertility levels; old and new farming techniques along with video tutorials for the usage of farming machinery; government and market policies; expert database generated from researchers' experiments and studies for concerns related to agriculture. It contains three broad database types: textual, pictorial, video graphic and social media derived solution knowledge base. The knowledge acquisition system looks for the requested user information in the knowledge base and integrates it with expert opinion to provide personalized solutions. It stores all the newly generated data for record maintenance and keeps updating it by acquiring new information through the user system interaction and latest updates through reliable sources including government, market giants, and researchers.

\section{Personal Knowledge Base}

The routine farm management data, crop information, per hectare yield, work division among labour, farm expenditure and farmrelated personal data of the user gets stored in the personal knowledge base. It also includes a backup of the user's historical queries and the best solutions so that it can be readily accessed. The user has the option to ask their friends and family to share their farm details in the personal knowledge base so that they can learn and improve based on techniques implied by each other. The whole information shared between the users is encrypted and protected by the application for providing it only to the approved users. It helps them make a comparison in the farming methodology and the development of a friendly online learning community.

\section{Inference Engine}

After creating the knowledge base using the knowledge acquisition system, the inference engine is used to make a reasoning mechanism with defined algorithms to utilize it. It ensures delivery of the proper query sequencing as applied by the user to the knowledge base to seek the best problem-solving solution. It matches the knowledge base against the criteria provided by the user and determines which rules are applicable. The system does not make any assumptions, and the final solution relies on the quality of the user's information. The inference engine displays the best possible solution to the user and allows them to respond to the query according to their expertise. The community farmers can also check the query and respond according to their similar query handling experience. The user then can choose either the system generated solution, real-time expert advice, or go with the farmers' community response. The system displays a confidence factor for each solution, and once the user adopts a solution, it gets saved to the localized 
database for easier accessibility of the farmer. The inference engine uses expert systems, qualitative approaches, parametric systems, statistical methods, hybrid approaches, networks, and optimization tools, among others depending on the individual case scenario to provide the best possible solution.

\section{Traditional KBS Inference}

The traditional KBS inference engine applies logical rules to the knowledge base to conclude new information. Each new query raised by the user triggers additional rules in the inference engine and finds a solution either by starting with known facts and asserting a new fact or start with goals and then moves backward to match it with facts that can help achieve the solution goals (Devraj \& Jain, 2011). The expert system analyses whether the query is a question, suggestion, general information or addition to the farm records. The data is then accessed based on various algorithms that are part of the traditional KBS inference to draw data from the knowledge base to deliver requested information to the user. It functions even without internet connectivity giving more accessibility and mobility to the user.

\section{Social Media Inference}

User can share their information and queries in real-time with their community through the discussion forum. The online users can look at the query and can make their suggestions according to the expertise. The social media inference makes sure that the information provided inclines with the user's request and combines online data, traditional knowledge base, and crowdsourcing database latest and best-fitted solution the query. The newly generated data is then stored in the knowledge base for improving the system generated solutions.

\section{User Interface}

Farmers interact with the expert agricultural system through its user-friendly interface to get solutions for their queries; experts use the interface to interact with farmers and answer their queries in real-time through the social media-enabled discussion forum. The user interface has two segments: personal user interface and social media interface. The personal user interface has profile and settings features which can be used to access the farm management features, offline features and data storage to access information about a particular concern. Figure 1 shows the model division of the user interface. The social media interface has features of search and community, which opens the doors to connect with the rest of the world in real-time. The modern query handling interface makes it possible for the user to access both worlds with offline and online query handling. The generic and static knowledge-based system can be used alone in offline mode by the user to find personalized solutions for a problem based on the expert KBS database. The improved expert knowledge-based system, on the other hand, adds another layer of latest and updated information from experts in real-time so that the user gets the maximum advantage of the online social media interaction by providing local, personalized solutions to the farmers in the dynamic real-time settings. The system's database gets updated and synced to the cloud in the form of suggestions given by the local community in the discussion forum as it helps in identifying new farming techniques created by the farmers and understanding about latest technology in the agrarian sector so that appropriate changes can be made in the database.

\section{Personal Interface}

The personal user interface provides a customized space for the users to add information related to farm management, access their crop details, compare their crop production with previous year data, look into details of farm resources, among other functions. It helps the users in record-keeping, adjust the platform to changing interaction styles and personalize it according to their usage needs.

\section{Social Media Interface}

Social media's mass influence raises awareness about various issues and technological updates that a farmer might face while engaging in farming. It also helps the farmers get recognized in their local community based on their production techniques and awareness about the latest farming information. The social media interface acts as a platform that involves engagement with harvest buyers on a broader scale, thus creating an opportunity to use it for social commerce and get opinions and feedback for their produce. Social media interface assists in getting real-time and localized suggestions about a farmer's concerns. They can share their ideologies about government policies, responses to consultations, organized thoughts, and beliefs with the agrarian community. The farmers can create a social face value and get involved in agricultural research through crowdsourcing. The social media interface stores a local copy of an individual farmer's interaction history on the device and sync it with the cloud to include in the crowdsourcing and personal knowledge base.

\section{Technical framework}

Farm-n-Pedia is an android based mobile application that is planned and created to fulfill the needs of the farmers' community and provide a means to improve their agricultural productivity and create an engaging farming experience for them. The functioning of current smartphone apps to assist farmers has been tracked, and the end-user feedback has been reviewed to establish a single portal that meets all the needs of farmers. Real-time solutions are provided to users through an expert system, and all data is stored in the cloud to make it accessible for the user from any device. Farmers' preferences were considered in designing the interactive user interface, system technical design and content development. It was built through a variety of versions of the smartphone application. The user with basic knowledge of cell phone service and agriculture was kept in mind when designing the software. Agricultural 
experts helped build the expert system interfaces and provide hands-on support for upgrading the mobile application features. An informational and convenient mobile application with relevant tutorials is designed to provide ease of use to the end-user. All the information intended to produce the app's content has been accumulated through agrarian, market and government experts for keeping our databases up to date.

\section{Resources}

Flutter toolkit (Google Inc., 2018) and coding languages like Dart and Python are used to work on the mobile application's development. Flutter is used to build full-featured applications, including network support, storage, cameras, expert networks, geolocation, and more. Other relevant software and technology are also used to improve the mobile app's functionality, and Android Studio is used to handle the whole app project and testing process. With the first phase, the core features of the software and the session configuration were checked. Further iterations were made to validate the device architecture, focusing on immersive app functionality, including cameras and images. Advanced features such as the availability of real-time data, social media interaction, a map view of the farms was later integrated into the prototype.

\section{System architecture and implementation}

The framework architecture is developed to provide support for agricultural activities through the single-stop Farm-n-Pedia mobile app. A readily identifiable icon is designed to make the system user-friendly. Navigation of the software is effortless for the consumer. After opening the app, a protected authentication option is available to the user, and then the user is linked to the app dashboard, where all functions can be explored. At the outset, a tutorial is given on how to use the mobile application. Follow-up pages can be accessed at the user's discretion from the app homepage.

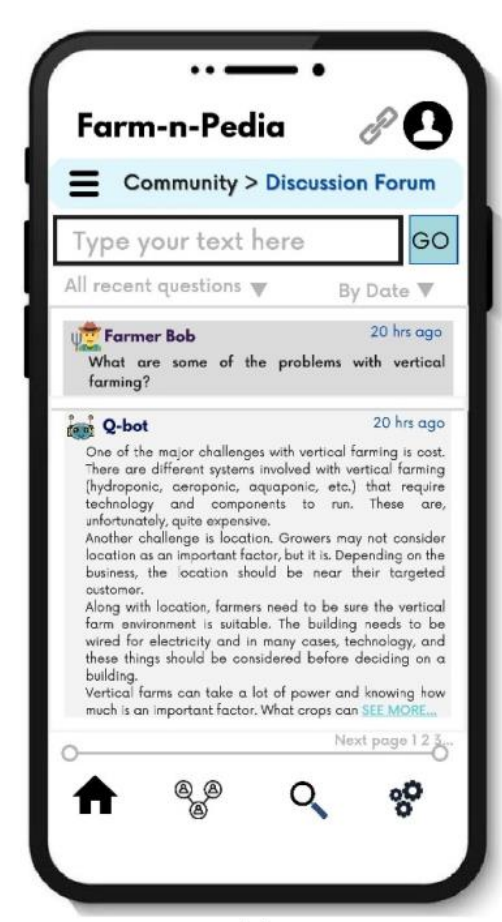

(a)

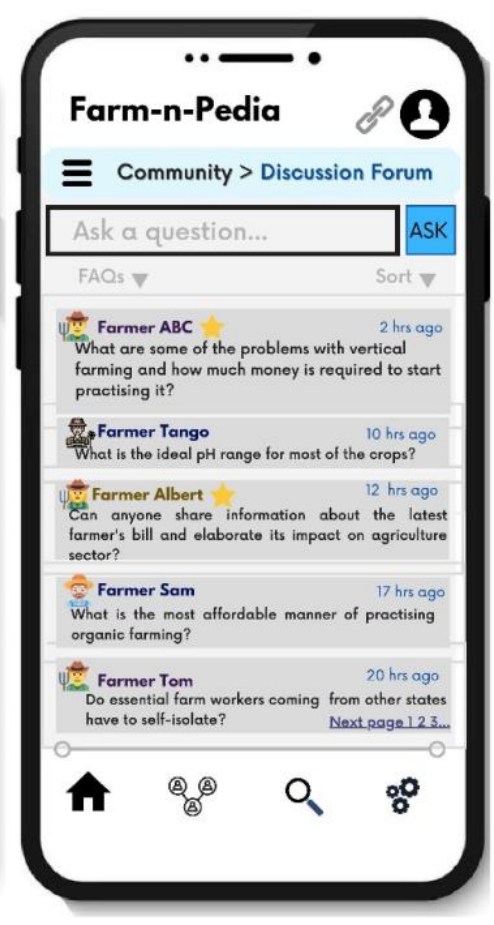

(b)

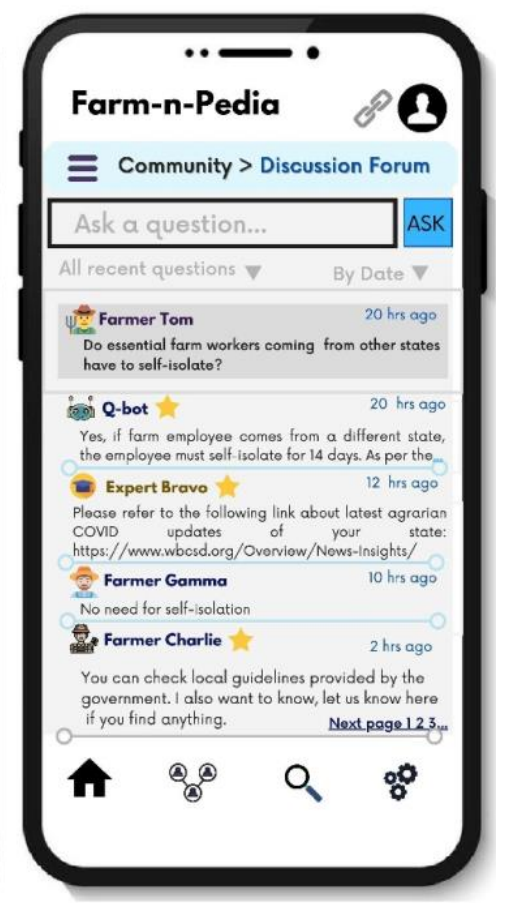

(c)

Figure 2 Mobile app screenshots depicting expert KBS (offline) and social media mode (online) in the discussion forum

Figure 2 shows the comparison of the traditional knowledge-based system with our modern and interactive expert knowledge-based system. Figure 2(a) shows the traditional portal used to ask questions in offline mode. It shows a question asked by the farmer and response provided by Q-bot (expert system) based on data stored in the knowledge-base. Figures 2(b) and 2(c) depict the online social-media enabled discussion forum model, allowing the user to directly interact with the local community to ask about their concerns. In figure 2(b), you can see many questions being asked by the farmers. Our mobile app gives the convenience to ask a question in textual and/or pictorial form, and then the expert system responds to the user based on the real-time response from the farming community and experts. Suggestions by other app users have a feasibility and reliability rating that allows them to apply the solutions in a well-informed manner. Real-time discussions are also supported through the discussion forum. Figure 2(c) shows a real-time discussion on the question asked by Farmer Tom, as seen in Figure 2(b). Farmers have been replying to the question according to their knowledge, and the expert has also replied to it. The expert system keeps a record of all the answers on the back end under the social media knowledge-base to be accessed by a user later on. The mobile application has a self-learning system, 
improving as more users add their insights into the discussion forum. A 'star' is shown in front of the farmers and experts based on their agrarian sector capability. The 'star' is allotted to the users based on their accurate information-sharing ability.

The mobile application's layout makes it unique and easily compatible with all smartphones. We have designed and used easily recognized icons considering the whole agrarian community. The icons are aesthetic and can be easily differentiated from all app features to make it simple and easy to use. The mobile application has an extensive range of features to accommodate various sorts of expectations of the farmers.

\section{Detailed Design Description}

Cloud-storage makes it easy for the users to sign-on from any smartphone device and access their stored data or seek new information. Figure 3 shows the system architecture and use case, which shows how the commands are accepted and used by the expert system for providing a solution to the users. The mobile application allows the user to access offline encyclopedic features and pre-download tutorial videos to watch later, even without internet connectivity. If a user generates data in offline mode, it gets stored in cache memory and gets uploaded to the user's personalized database as soon as an internet connection is made available. The system does periodic database updates to keep the latest news items and weather forecasts accessible for the users. Discussion forum provides real-time engagement opportunity to users with internet connectivity. The user can share any issue, latest information, opinion, belief and production updates to their local community for experiencing values of involvement, trust and reliability from all other users. Thus, the mobile application provides personalized solutions and aims to bridge the information gap between farmers and experts and create general awareness about the agriculture sector.

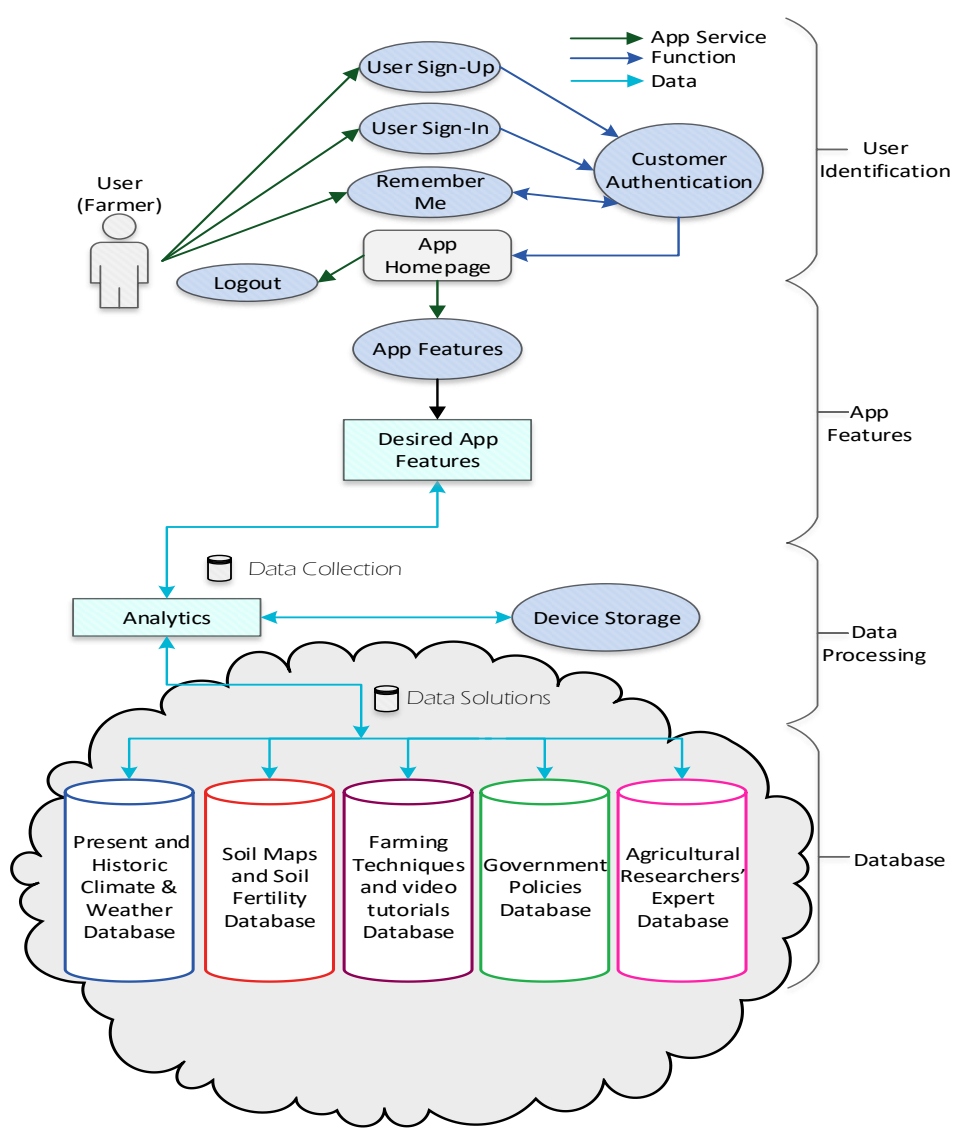

Figure 3: Architecture of 'Farm-n-Pedia'

Figure 4 depicts the mobile app's homepage with multiple feature heads like profile, community, search and settings. Each of the feature tabs has multiple support options for the farmers to assist them in daily activities. It gives them the option to choose multiple features depending on their needs. The user can access offline and online features through the user-friendly interface. The user can check daily weather and news updates to be informed about how they can enhance their farming experience and strategize their farming methods to increase productivity. 


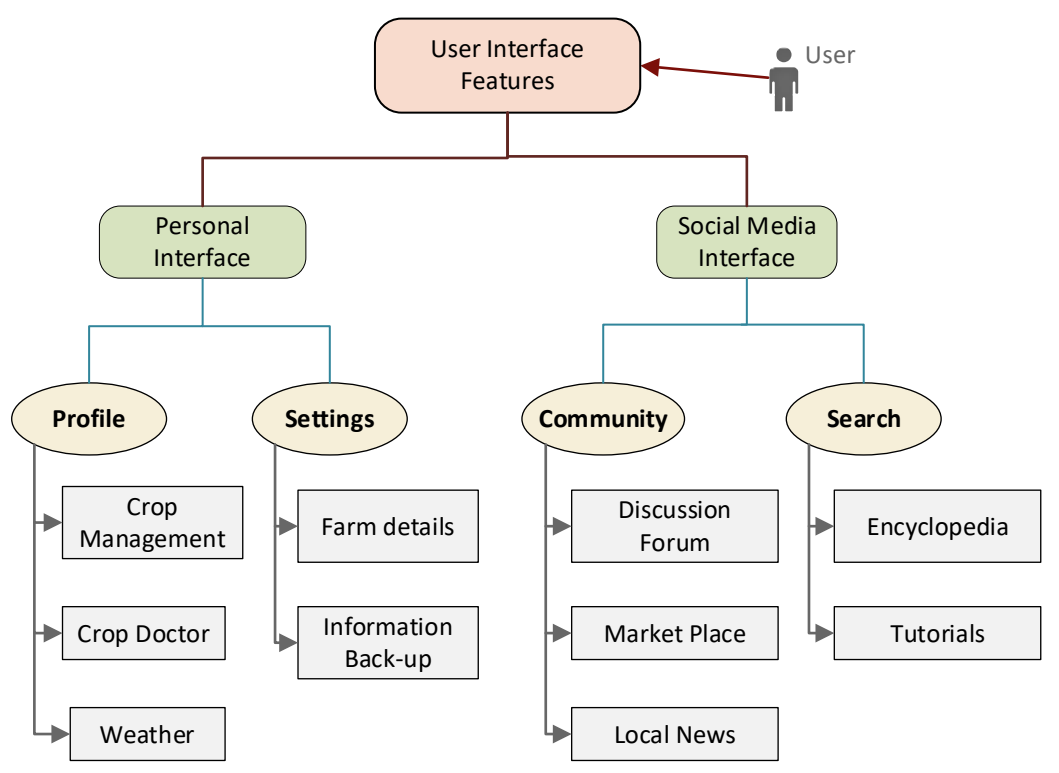

Figure 4: Homepage sections and features of 'Farm-n-Pedia'

\section{Discussions}

The study explores the need and development of Farm-n-Pedia, a mobile application designed to increase agricultural productivity. This paper aims to propose a mobile app prototype that serves as a single platform to address all the issues that farmers face in their day-to-day farming activities and provide a user-friendly agricultural management system that will increase farming productivity. It also focuses on developing a thriving agrarian community through which farmers can get recognized for their efforts, be more knowledgeable and make research contributions by engaging in crowdsourcing practices with agricultural experts. We integrated social media as part of the knowledge base for the expert agricultural KBS. The proposed model can provide mobile accessibility in a personalized and dynamic manner to keep the users updated about the trends in the agriculture sector. It also fulfils the localized informational needs of the farmers, which helps in performing day-to-day activities.

Theoretically, the proposed application model brings together the knowledge-based system, social media engagement and data collection strategies all under one hood. It strengthens the application of knowledge-based systems and builds an integrated and consistent platform that combines knowledge from researchers and experienced farmers into the knowledge base. It opens new research avenues to understand the combined usage of social media and the knowledge-based system.

Practically, one crucial feature of mobile apps in agriculture is the presence of the human interface, suggesting a reliance on the human factor for the dissemination of information to farmers so that they can work smartly and increase farm yields. There is also a need to realize how much technologies can satisfy farmers' needs so that better and viable long-term solutions can be created. Our objective is to meet the demands of farmers, encourage the actual use of the mobile app, and have a meaningful effect on crop productivity and increase social engagement. The effect of this research is an interactive app for farmers to assist in regional languages, on-the-go access to any information needed, the ability to implement new technologies and the advancement of farming techniques.

Managerially, the study opens a new market opportunity for the farmers to directly get in touch with consumers and market giants to sell their products and generate profits. It leads to the development of agricultural practices in India and aims to increase agricultural production for farmers. It also provides an opportunity for the farmers to work as citizen scientists by collaborating with research scientists in the data collection process and opening new research avenues for the agriculture sector. It would also aid in the economy's socio-economic growth and change the agricultural sector in India. Companies engaged in IT and agriculture should work together to create standard networks to support farmers.

\section{Conclusions}

This smartphone application is currently in the development process and has a few technical issues that we are currently fixing. It creates effective expert support systems for Indian farmers who are essential to maintaining this radical mobile application. An actual assessment can further validate the mobile application with Indian farmers to determine the mobile agricultural management system's efficacy and fully update and finalize the application architecture. Although mobile technology usage for farming can be revolutionary, network connectivity in the rural areas is not always good, and it might take a few years for the telecom companies and the government to address this issue. Due to this reason, we have kept synchronization and offline information-seeking capability 
in the mobile application. We have added real-time app features like location sharing and connecting with agricultural experts and fellow farmers. Thus, we have incorporated high-frequency synchronization for real-time online functions and offline data synchronization for pre-stored database features. The paper highlights the use of the new google toolkit to create applications and the nature of the platform as a one-stop solution to all the problems that farmers face day-to-day in agricultural practices. It lays out guiding principles for the design of mobile applications, and it also highlights other technical and contextual qualities that need to be addressed in the design phase of a mobile application. It also lays out guiding principles for implementing mobile solutions and how to perform design-based studies in mobile learning.

\section{Acknowledgement}

We want to acknowledge that an earlier version of this paper was presented on the International Conference on Human-Computer Interaction (HCII 2020), July 19-24, Copenhagen, Denmark. The current version of the manuscript is significantly different from the early version because the conference version described a traditional KBS while the current version describes a new KBS that incorporates a social media (crowdsourcing) system in the knowledge base and the interface design. This research did not receive any specific grant from funding agencies in the public, commercial, or not-for-profit sectors.

\section{References}

Allahyari, M. S., \& Chizari, M. (2010). Potentials of New Information and Communication Technologies (ICTs) in Agriculture Sector. Journal of Agricultural Science and Technology, 4(4), 115-120.

Armstrong, L. J., Gandhi, N., \& Lanjekar, K. (2012). Use of Information and Communication Technology (ICT) tools by rural farmers in Ratnagiri District of Maharastra, India. Proceedings - International Conference on Communication Systems and Network Technologies, CSNT 2012, 950-955. https://doi.org/10.1109/CSNT.2012.202

Balkrishna, B. B., \& Deshmukh, A. A. (2017). A Study on Role of Social Media in Agriculture Marketing Use of WhatsApp. Global Journal of Management and Business Research: E-Marketing, 17(1), 283-287. https://doi.org/10.18782/2320-7051.7722

Beza, E., Silva, J. V., Kooistra, L., \& Reidsma, P. (2017). Review of yield gap explaining factors and opportunities for alternative data collection approaches. European Journal of Agronomy, 82, 206-222. https://doi.org/10.1016/j.eja.2016.06.016

Devraj, \& Jain, R. (2011). PulsExpert: An expert system for the diagnosis and control of diseases in pulse crops. Expert Systems with Applications, 38(9), 11463-11471. https://doi.org/10.1016/j.eswa.2011.03.020

Dwivedi, S., Parshav, V., Sharma, N., Kumar, P., Chhabra, S., \& Goudar, R. H. (2013). Using technology to make farming easier and better: Simplified E-Farming Support (SEFS). 2013 International Conference on Human Computer Interactions, ICHCI 2013, 248002, 1-6. https://doi.org/10.1109/ICHCI-IEEE.2013.6887806

Google Inc. (2018). Flutter - Beautiful native apps in record time. Google. https://flutter.dev/

India Brand Equity Foundation. (2020). Agriculture and Allied Industries. www.ibef.org

Information Solutions, A. (2015). Mobile services could enhance income of farmers. E-Governance Electronic Data Processing, 12.

Jain, D. S., \& Neeraj Kumar, P. (2017). Assessment of Knowledge Level, Need and Impact of ICTs among Farmers in Different Aspects of Agriculture at Talera Block of Bundi District in Rajasthan. International Journal of Research in Commerce, IT \& Management, 7(7), 92-103.

Joan, R. (2015). Artificial Intelligence and Knowledge Based Systems Technologies. I-Manager's Journal on Information Technology, 4(1), 1-6.

Kahasha, E. I., \& Zuva, T. (2020). Mobile Crowdsourcing in Crop Production for Farmers in Rural Areas of the South Kivu. Proceedings of the 2nd International Conference on Intelligent and Innovative Computing Applications (ICONIC'20). Plaine Magnien, Mauritius, 6 pages.

Klerkx, L.; Hall, A. and Leeuwis, C. (2009). Strengthening Agricultural Innovation Capacity: Are Innovation Brokers the Answer? In United Nations University. UNU-MERIT Working Paper Series \#2009-019.

Lakshmanan, R. (2019). Service Sector in India - Statistics and Overview | Invest India. https://www.investindia.gov.in/team-indiablogs/service-sector-india-paradigm-shift

Marimuthu, R., Alamelu, M., Suresh, A., \& Kanagaraj, S. (2017). Design and development of a persuasive technology method to encourage smart farming. 2017 IEEE Region 10 Humanitarian Technology Conference (R10-HTC), 21-23. https://doi.org/10.1109/R10-HTC.2017.8288930

Meera, S. N., Jhamtani, A., \& Rao, D. U. M. (2004). Information and Communication Technology in Agricultural Development: A Comparative Analysis of Three Projects from India. Agricultural Research \& Extension Network (AgREN), 135. http://dlc.dlib.indiana.edu/dlc/bitstream/handle/10535/4915/agrenpaper_135.pdf?sequence=1\&isAllowed=y

Megan O, \& Donnell. (2013). Using ICT to Enhance Marketing for Small Agricultural Producers.

Mittal, S. C. (2016). Role of Information Technology in Agriculture and its Scope in India. Indian Farmers Fertiliser Cooperative Limited.

Morris, W., \& James, P. (2017). Social media, an entrepreneurial opportunity for agriculture-based enterprises. Journal of Small Business and Enterprise Development, 24(4), 1028-1045. https://doi.org/10.1108/JSBED-01-2017-0018 
Murria, P. (2018). Indian Agrarian Economy or Suicide Economy: Is There Any Way Out? Productivity, 59(1), 10-20. https://doi.org/10.32381/prod.2018.59.01.2

Mwakaje, A. (2010). Information and Communication Technology for Rural Farmers Market Access in Tanzania. Journal of Information Technology Impact, 10.

Narechania, A. (2015). KisanVikas-Android Based ICT Solution in Indian Agriculture to Assist Farmers. Proceedings of the 7th International Conference on Information and Communication Technologies in Agriculture, Food and Environment (HAICTA) 2015, Kavala, Greece, 17-20.

NOAA. (2014). GPS.gov: Agricultural Applications. https://www.gps.gov/applications/agriculture/

Pechrová, M., Lohr, V., \& Havlíček, Z. (2015). Social Media for Organic Products Promotion. AGRIS On-Line Papers in Economics and Informatics, 7(1), 1-10. https://doi.org/10.22004/ag.econ.207055

Rafea, A., \& Shaalan, K. (1996). Using expert systems as a training tool in the agriculture sector in Egypt. Expert Systems with Applications, 11(3), 343-349. https://doi.org/10.1016/S0957-4174(96)00049-8

Rapp, A., Beitelspacher, L. S., Grewal, D., \& Hughes, D. E. (2013). Understanding social media effects across seller, retailer, and consumer interactions. Journal of the Academy of Marketing Science, 41(5), 547-566. https://doi.org/10.1007/s11747-0130326-9

Rhoades, E., \& Aue, K. (2010). Social Agriculture: Adoption of Social Media by Agricultural Editors and Broadcasters. Southern Association of Agricultural Scientists Conference, February, Orlando, FL.

Saravanan, R., Sulaiman, R. V., Davis, K., \& Suchiradipta, B. (2015). Navigating ICTs for extension and advisory services. Note 11 Global Good Practice. Notes for Extension and Advisory Services. Lindau; Switzerland: GFRAS.

Simmons, G. J., Durkin, M. G., Pauric, M., \& Armstrong, G. A. (2007). Determinants of internet adoption by SME agri-food companies. Journal of Small Business and Enterprise Development, 14(4), 620-640. https://doi.org/10.1108/14626000710832730

Singh, Ajoy Kumar, Singh, A. K., Kumar, R., Prakash, V., \& Sundaram, P. K. (2017). Indian Cereals Saga: Standpoint and Way Forward. Journal of AgriSearch, 4(1). https://doi.org/10.21921/jas.v4i1.7411

Singh, Anil Kumar, Upadhyaya, A., Kumari, S., Sundaram, P. K., \& Jeet, P. (2020). Role of Agriculture in making India $\$ 5$ trillion Economy under Corona Pandemic Circumstance. Journal of AgriSearch, 6(02), 54-58. https://doi.org/10.21921/jas.v6i02.18097

Singh, K. M., Kumar, A., \& Singh, R. K. P. (2015). Role of Information and Communication Technologies in Indian Agriculture: An Overview. SSRN Electronic Journal, October 2017. https://doi.org/10.2139/ssrn.2570710

Singh, P. K., \& Hussain, D. M. S. (2018). Expert System for Crop Selection in Agriculture: A Critical Review. International Journal of Advanced Research in Computer Science, 9(2), 143-146.

Singhal, M., Verma, K., \& Shukla, A. (2011). Krishi Ville - Android based solution for Indian agriculture. International Symposium on Advanced Networks and Telecommunication Systems, ANTS. https://doi.org/10.1109/ANTS.2011.6163685

Sran, A. K., Komiak, S. Y. X., \& Manzoor, S. (2020). Mobile Based Agricultural Management System for Indian Farmers. Lecture Notes in Computer Science (Including Subseries Lecture Notes in Artificial Intelligence and Lecture Notes in Bioinformatics), 12202 LNCS, 162-174. https://doi.org/10.1007/978-3-030-49757-6_11

Topp, G. C., Davis, J. L., Bailey, W. G., \& Zebchuk, W. D. (1984). The Measurement of Soil Water Content using a Portable TDR Hand Probe. Canadian Journal of Soil Science, 64, 313-321.

United Nations. (2019). World Population Prospects 2019. In Department of Economic and Social Affairs, Population Division (2019). World Population Prospects 2019: Highlights (ST/ESA/SER.A/423) (Issue 141). http://www.ncbi.nlm.nih.gov/pubmed/12283219

Van Etten, J., de Sousa, K., Aguilar, A., Barrios, M., Coto, A., Dell'Acqua, M., Fadda, C., Gebrehawaryat, Y., van de Gevel, J., Gupta, A., Kiros, A. Y., Madriz, B., Mathur, P., Mengistu, D. K., Mercado, L., Mohammed, J. N., Paliwal, A., Pè, M. E., Quirós, C. F., ... Steinke, J. (2019). Crop variety management for climate adaptation supported by citizen science. Proceedings of the National Academy of Sciences of the United States of America, 116(10), 4194-4199. https://doi.org/10.1073/pnas.1813720116

Veeranjaneyulu, K. (2014a). KrishiKosh: an institutional repository of National Agricultural Research System in India. Library Management, 35(4/5), 345-354. https://doi.org/10.1108/lm-08-2013-0083

Veeranjaneyulu, K. (2014b). KrishiKosh: an institutional repository of National Agricultural Research System in India. Library Management, 35(4/5), 345-354. https://doi.org/10.1108/lm-08-2013-0083

Wang, S., Di Tommaso, S., Faulkner, J., Friedel, T., Kennepohl, A., Strey, R., \& Lobell, D. B. (2020). Mapping Crop Types in Southeast India with Smartphone Crowdsourcing and Deep Learning. Remote Sensing, 12(18), 2957. https://doi.org/10.3390/RS12182957

Publisher's Note: SSBFNET stays neutral with regard to jurisdictional claims in published maps and institutional affiliations.

\section{(a) (1)}

() 2021 by the authors. Licensee SSBFNET, Istanbul, Turkey. This article is an open access article distributed under the terms and conditions of the Creative Commons Attribution (CC BY) license (http://creativecommons.org/licenses/by/4.0/). International Journal of Research in Business and Social Science (2147-4478) by SSBFNET is licensed under a Creative Commons Attribution 4.0 International License. 